\title{
Effects of an injury and illness prevention program on occupational safety behaviors among rice farmers in Nakhon Nayok Province, Thailand
}

This article was published in the following Dove Press journal:

Risk Management and Healthcare Policy

8 March 2014

Number of times this article has been viewed

\author{
Sapsatree Santaweesuk ${ }^{1,2}$ \\ Robert S Chapman' \\ Wattasit Siriwong ${ }^{1,3}$ \\ 'College of Public Health Sciences, \\ Chulalongkorn University, Bangkok, \\ Thailand; ${ }^{2}$ Srinakarinwirot University \\ Ongkharak Campus, Nakhon Nayok, \\ Thailand; ${ }^{3}$ Thai Fogarty ITREOH \\ Center, Chulalongkorn University, \\ Bangkok, Thailand
}

\begin{abstract}
The objective of this study was to determine the effects of an Injury and Illness Prevention (IIP) program intervention on occupational safety behavior among rice farmers in Nakhon Nayok Province, Thailand. This was a quasi-experimental study in an intervention group and a control group. It was carried out in two rice farming communities, in which most people are rice farmers with similar socio-demographic characteristics. Multistage sampling was employed, selecting one person per rice farming household. The intervention group was 62 randomly selected rice farmers living in a rural area; another 55 rice farmers served as the control group. A structured face-to-face interview questionnaire was administered to participants to evaluate their safety behaviors in four areas: equipment use, pesticide use, ergonomics, and working conditions. The 2 -week intervention program consisted of four elements: 1) health education, 2) safety inspection, 3) safety communication, and 4) health surveillance. Data were collected at baseline and 4 months after the intervention (follow-up). We used a general linear model repeated-measures analysis of variance to assess the mean difference between baseline and follow-up occupational safety behavior points between the intervention and control groups. Pesticide safety behaviors significantly increased in the intervention group compared with the control group. Ergonomics and working conditions points also increased in the intervention group, but not significantly so. The equipment use score decreased in the intervention group. It is necessary to identify and develop further measures to improve occupational safety behaviors. Some methods, such as effective risk communication, could be added to increase risk perception.
\end{abstract}

Keywords: occupational safety behaviors, rice farmers, safety program, injury and illness prevention program

\section{Introduction}

Thailand is a Southeast Asian country in which occupational health and safety issues are important. High-risk occupations exist in both agricultural and industrial sectors. ${ }^{1}$ Rice farming has historically been, and is still today, the main occupation of Thai agriculturists. Nowadays, rice farmers use rice cultivation methods that differ from those in the past. Technologies have been implemented to find ways to replace human and animal labor with machines. In response to higher competition and a different environment, larger volumes of pesticide are used, equipment use can be unsafe, and ergonomic conditions at work are poor. ${ }^{2-5}$ Previous studies have found injury and illness among rice farmers. ${ }^{6-11}$ Three major occupational health and safety problems have been found among farmers: symptoms from pesticide exposure, musculoskeletal problems during various processes, and injuries during various processes. ${ }^{6} \mathrm{~A}$ third of the injuries that cause rice farmers to miss work are sprains and strains, and a quarter
Correspondence:Wattasit Siriwong College of Public Health Sciences, Chulalongkorn University, IOth floor, Institute Building 3, Soi Chulalongkorn 62, Phyathai Road, Pathumwan, Bangkok 10330, Thailand

Tel +6622188182

Fax +6622556046

Email wattasit.s@chula.ac.th 
are back injuries. ${ }^{6}$ In addition, work-related health conditions have been documented in agricultural workers, including musculoskeletal and traumatic injuries, respiratory conditions such as allergies and asthma, dermatitis, pesticide poisonings, and heat-related illnesses. ${ }^{6}$ Occupational health and safety problems among rice farmers may result from unsafe behaviors and unsafe acts or practices of workers resulting in incidents that can cause injuries. At present, rice farmers tend not to change their safety behaviors, despite knowing that inappropriate behavior can affect their health. ${ }^{6}$ These behaviors are related to agrochemical exposure, such as the use of faulty spraying equipment or lack of attention to safety precautions. ${ }^{11}$ In addition, studies on programs that encourage improved occupational safety behaviors in these farm workers are limited. The findings of previous studies may not cover all types of occupational hazards. Therefore, we developed an intervention program to reduce workrelated injuries and illnesses, and to improve appropriate safety behavior. The intervention program was based on the theories of accident causation, ${ }^{12-16}$ and was modified as appropriate for the specific study setting. Moreover, many intervention programs are provided by research teams with no interaction between participants or between participants and study personnel. Thus, this program used a participatory approach in the community. Four elements were covered: 1) health education, 2) safety inspection, 3) safety communication, and 4) health surveillance. It was expected that this program could offer rice farmers an effective and efficient approach to improving safety behavior and their work environment. In 2010, Nakhon Nayok Province reported a morbidity rate of $6.8-10.2$ per 100,000 population as a result of pesticide poisoning. ${ }^{17,18}$ Few studies have been conducted to explore the prevalence of injury and illness among rice farmers. Causes of injury and illness include cuts/pinches from sharp equipment/machinery, dizziness after using pesticides, and bites or stings from venomous animals. Hospital visits for this condition are increasing. ${ }^{19}$ The objective of this study was to determine the effects of an injury and illness prevention (IIP) program on the occupational safety behavior among rice farmers in Nakhon Nayok Province, Thailand.

\section{Methods}

This quasi-experimental study was conducted in two communities in Ongkharak district, Nakhon Nayok Province, Thailand. This district is surrounded by irrigation canals and a national irrigation system that enables the cultivation of rice and other crops all year long. ${ }^{20}$ The district comprises 61,874 households, 26,656 (43.1\%) of which are agricultural households, and most of these are rice farmers. ${ }^{21}$ Study participants were rice farmers from two communities. A total of 145 participants were calculated with power and sample size calculations ${ }^{22}$ and developed from a previous study, ${ }^{23}$ increased by $10 \%$ to account for dropouts. Of these, $117(80.7 \%)$ completed the study (Figure 1). We selected one person per rice farming household. The inclusion criteria were rice farmers involved in all processes to do with growing rice, including: 1) land-preparation processes, 2) soaking and scattering of seed/application of fertilizers, 3) mixing and spraying of pesticides, 4) sowing of fertilizer, and 5) harvesting of rice. All participants had lived in the study area for at least 6 months. The recruited farmers were willing to participate in this research and provided informed consent. A total of 62 rice farmers participated in the intervention and another 55 served as the control group. A structured face-to-face interview questionnaire was administered. All participants were interviewed face-to-face, to characterize their occupational safety behaviors at work. Seven community health workers, known in Thailand as village health volunteers (VHVs) participated in the research. The selection criteria for VHVs were education level equal to or higher than high school (grade 9) and no communication problems. Their duties were to inspect workplace safety and to visit the home once a month. During a home inspection, if the health volunteers found inappropriate behavior or unsafe working conditions that might cause damage, village health volunteers were to suggest ways by which the situation could be improved, to the rice farmer.

The study was conducted in three phases: 1) preliminary data, 2) development and intervention implementation, and 3) program evaluation.

\section{Phase I: preliminary data}

1. We carried out a literature review of occupational injuries and illnesses among rice farmers in Thailand, and included research, reports, and statistics related to occupational injury and illness. We collected secondary data from the Health Promoting Hospital, including medical history and data records of injury and illness among agriculturists over 5 years.

2. We used a rapid assessment process to explore the prevalence of injury and illness at work among the agriculturists. The process consisted of community observation, focusing on their working conditions and activities.

3. We collected baseline data for rice farmers, including general information and occupational safety behaviors. 


\section{Phase 2: development and implementation of intervention}

We used the information from phase 1 to develop and implement an intervention program. The intervention program took place over 2 weeks and consisted of four elements: 1) health education, 2) safety inspection, 3) safety communication, and 4) health surveillance.

\section{Phase 3: program evaluation}

In phase 3, we determined the effects of the intervention program by measuring and comparing changes in mean behavior points from baseline to follow-up in the intervention and control groups (Figure 2).

\section{Tools and evaluation}

The Thai questionnaire was developed after the literature review, ${ }^{5,24-26}$ and the content was validated by three experts. The aim was to determine occupational safety behavior points before the intervention program and at follow-up 4 months after the intervention. The questionnaire included 36 interview items, covering four aspects of occupational hazards: 1) equipment use, 2) pesticide use, 3) ergonomics, and 4) working conditions. All participants were interviewed face-to-face and chose one point from a four-point Likert scale to rank frequency of practice (always, sometimes, rarely, or never). Examples of these questions are as follows:

1. Equipment use

- You decide how heavily you load a tractor

- You check an electric plug both before and after work

- You keep sharp equipment in the same place as other equipment

- You remove guards from a machine.

2. Pesticide use

- You read the instructions before you start working with pesticides

- You smoke while working with pesticides

- You wash your hands carefully after using pesticides

- You keep pesticides away from food and beverages.

3. Ergonomics

- You choose work methods to alternate standing and sitting and to avoid bending and squatting postures as much as possible

- You provide containers or baskets of appropriates sizes to carry materials and farm products

- You carry heavy weights a long distance without support equipment

- You work in awkward positions for long periods.
4. Working conditions

- Work area is maintained safely (ie, walkways clear, materials and tools organized)

- You are aware of animals, insects, or worms that may harm humans

- You avoid exposure to excessive heat.

\section{Structure of IIP program}

The IIP program in this study was based on accident causation theories and modified to maximize appropriateness for the specific study setting. Central Thailand is the main producer of rice, so this was where we located the study site. The irrigation technology in most villages has been updated, and the rice cultivation lasts for 4 months (rice is harvested 3 time per year). We planned that data would be collected for baseline characteristics and at follow-up 4 months after the intervention program. In addition, we applied a safety inspection model, mostly in factories, by replacing the factory foreman with VHVs involved in the study. Community radio is an accessible media that enables the villagers to distribute information; we used this tool to distribute safety information in the morning and afternoon. As some rice farmers were not able to read or understand the questionnaire, we collected the data via face-to-face interview. The objective of the program was to reduce work-related injuries and illnesses and to contribute to improved safety behavior and an improved working environment. The intervention program consisted of four elements over 2 weeks: 1) health education, 2) safety inspection, 3) safety communication, and 4) health surveillance.

\section{Element I: health education}

We applied health education methods to encourage risk perception and to teach correct safety behavior in rice farming. We aimed to empower those rice farmers with long-term conditions to take greater ownership and responsibility for their care and to have more control over the management of their long-term condition. This strategy was divided into two methods: group health education and individual health education. Group health education was delivered in 2 days in the first week of the intervention period, and included training on ergonomics, work-related injury and illness, safety and health care at work, pesticide use, Personal Protective Equipment (PPE), material handling and storage, machine safety/ equipment use, and working conditions. Individual health education was conducted in the second week by delivering a 2-hour session in the participants' homes in the intervention group. We selected specific issues such as working 
conditions or safety behavior that needed to be modified in rice farmers.

\section{Element 2: safety inspection}

Effective safety and health inspections are one of the most important incident/accident prevention tools. This narrow focus tends to ignore other causes of incidents, such as unsafe actions and personal factors. ${ }^{27}$ We provided 2 days of training for seven VHVs. After training, the VHVs inspected workplace safety and visited the participants' homes once a month. The inspection summary form was divided into four parts with 30 items, including equipment safety, pesticide use, work organization, and working conditions. In this way, VHVs could identify inappropriate behaviors and working conditions.

\section{Element 3: safety communication}

We informed rice farmers about occupational hazards, how they affect their health, and ways in which to protect themselves via an applied risk communication process. ${ }^{28,29} \mathrm{Com}-$ munity broadcasting, a safety manual, and safety posters were used in this study. We provided a program for broadcast in the early morning and afternoon $(5 \mathrm{pm})$ for 10 days. There were ten audio broadcasts related to safety at work, each 3-6 minutes long. In addition, we provided two safety manuals and one safety poster for the participants, when visiting their home. The contents of the safety communication was divided into four occupational hazard sections: equipment use, pesticide use, ergonomics, and working conditions.

\section{Element 4: health surveillance}

Rice farmers who were injured or became ill at work were required to report the injury or illness immediately to VHVs and health staff, and to follow these procedures as appropriate for the situation: 1) obtain medical attention, 2) complete the medical treatment form, and 3) when incidents occur at work, an investigation must be completed to identify the root cause and contributing factors that led to the incident. Health staff were required to complete any repairs and implement procedural changes to correct actions or conditions contributing to the incident. This may lead to the prevention of similar injury or illness incidents in the future.

\section{Data analysis}

SPSS (Statistical Package for the Social Sciences) for Microsoft $^{\circledR}$ Windows version (IBM Corporation, Armonk, NY, USA) was used for statistical analysis. The descriptive statistics frequency, percentage, mean, and standard deviation (SD) were used to describe participants' characteristics at baseline. Differences between baseline characteristics in the intervention and control groups were assessed by independent Student's $t$-test for continuous data and chi-square test for categorical data.

For each of the four types of occupational safety behavior score, the effect of the intervention is the difference between the intervention and control groups in the mean change from baseline to follow-up in that same score. General linear model repeated-measures analysis of variance (ANOVA) was used to quantify and test the statistical significance of the intervention effect for each type of score, and for the overall score. $P$-values $<0.05$ were considered statistically significant. Intervention effects were analyzed, both without adjustment and with adjustment for daily hours working with pesticides.

\section{Ethical considerations}

This study was approved by the institutional review boards of the Ethics Review Committee for Research Involving Human Research Subjects, Health Sciences Group, Chulalongkorn University, Thailand, Project No 061.2/55 COA No 153/2555. All participants were informed of the study objectives and that they had the right to withdraw from the study at any time, without any adverse consequences for them.

\section{Results}

\section{Participants' characteristics}

There were 145 participants originally enrolled in this study. Of these, $117(80.7 \%)$ completed the study (62 in the intervention group, 55 in the control group). Slightly more females $(51.3 \%)$ than males $(48.7 \%)$ took part. The mean age was $50.9 \pm 12.3$ years, and most participants were married (82.2\%). Most rice farmers $(76.1 \%)$ had graduated from primary school. Mean monthly family incomes were on average 12,028 Thai baht or \$US404; $23.1 \%$ of participants were current smokers. Their mean $( \pm \mathrm{SD})$ risk perception score was $246.6 \pm 59.2$ or 'moderate' level. The duration of rice farming was $27.4 \pm 13.1$ years, and working hours were $7.7 \pm 12.3$ hours per day. Farm sizes were $37.1 \pm 18.9$ rai or 14.8 acres. The mean duration of pesticide use since they became rice farmers was $20.5 \pm 10.5$ years, and daily hours working with pesticides was $2.7 \pm 1.1$ hours. Frequency of pesticide use per month was $3.2 \pm 4.3$, with a mean number of pesticide mix each time of $2.9 \pm 0.9$ types.

\section{Comparison of baseline characteristics}

As shown in Table 1, daily hours working with pesticides was significantly higher in the control group than in the 
Table I Participant characteristics at baseline $(n=117)$, by intervention status

\begin{tabular}{|c|c|c|c|}
\hline \multirow[t]{2}{*}{ Characteristic $^{\mathrm{a}}$} & \multicolumn{2}{|c|}{ Control group Intervention } & \multirow[t]{2}{*}{$P$-value } \\
\hline & $(n=55)$ & group $(n=62)$ & \\
\hline Sex & & & 0.300 \\
\hline Male & $24(43.6)$ & $33(53.2)$ & \\
\hline Female & $31(56.4)$ & $29(46.8)$ & \\
\hline Marital status & & & 0.674 \\
\hline Married & $46(83.6)$ & $50(80.6)$ & \\
\hline $\begin{array}{l}\text { Single/widowed/divorced/ } \\
\text { separated }\end{array}$ & $9(16.4)$ & $12(19.4)$ & \\
\hline Education & & & 0.660 \\
\hline $\begin{array}{l}\text { Never attended } \\
\text { school }\end{array}$ & $\mathrm{I}(\mathrm{I} .8)$ & - & \\
\hline Primary school & $4 \mathrm{I}(74.5)$ & $48(77.4)$ & \\
\hline Secondary school & $9(16.4)$ & $8(12.9)$ & \\
\hline $\begin{array}{l}\text { Equal to or higher } \\
\text { than high school }\end{array}$ & $4(7.3)$ & $6(9.7)$ & \\
\hline \multicolumn{3}{|c|}{ Monthly family income (Thai baht ${ }^{b}$ ) } & 0.213 \\
\hline$\leq 5,000$ & $24(43.6)$ & $15(24.2)$ & \\
\hline $5,001-10,000$ & $18(32.7)$ & $27(43.5)$ & \\
\hline $10,001-15,000$ & $3(5.5)$ & $6(9.7)$ & \\
\hline$|5,00|-20,000$ & $2(3.6)$ & $5(8.1)$ & \\
\hline$>20,000$ & $8(\mid 4.5)$ & $9(14.5)$ & \\
\hline Smoking cigarettes & & & 0.761 \\
\hline Yes & $12(21.80)$ & $15(24.20)$ & \\
\hline No & $43(78.20)$ & $47(75.80)$ & \\
\hline \multicolumn{4}{|l|}{ Characteristic $^{c}$} \\
\hline Age (years) & $52.76( \pm 13.69)$ & $49.19( \pm 10.84)$ & 0.119 \\
\hline Risk perception & $236.24( \pm 62.85)$ & $255.76( \pm 54.59)$ & 0.075 \\
\hline $\begin{array}{l}\text { Years working in } \\
\text { rice farming }\end{array}$ & $27.64( \pm \mid 4.38)$ & $27.24( \pm \mid 2.05)$ & 0.872 \\
\hline Working hours & $7.56( \pm 12.75)$ & $7.81( \pm 12.00)$ & 0.916 \\
\hline Farm size $\left(\mathrm{rai}^{\mathrm{d}}\right)$ & $38.47( \pm 19.19)$ & $35.85( \pm 18.80)$ & 0.458 \\
\hline $\begin{array}{l}\text { Duration of pesticide } \\
\text { use (years) }\end{array}$ & $21.02( \pm 11.68)$ & $20.03( \pm 9.39)$ & 0.614 \\
\hline $\begin{array}{l}\text { Daily hours working } \\
\text { with pesticides }\end{array}$ & $2.94( \pm 1.16)$ & $2.43( \pm 1.01)$ & 0.013 \\
\hline $\begin{array}{l}\text { Frequency of pesticide use } \\
\text { per month }(n)\end{array}$ & $2.82( \pm 2.74)$ & $3.47( \pm 5.30)$ & 0.416 \\
\hline $\begin{array}{l}\text { Mean number of pesticide } \\
\text { mixed each time }\end{array}$ & $3.04( \pm 0.84)$ & $2.74( \pm 1.02)$ & 0.094 \\
\hline
\end{tabular}

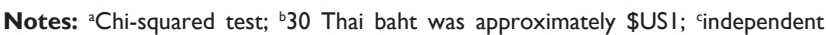
Student's $t$-test; 2.47 rai $=$ I acre. Data are presented as n (\%) or mean ( $\pm S D)$. Abbreviation: SD, standard deviation. intervention group $(P=0.013)$. This was the only characteristic that differed significantly between the groups.

\section{Effectiveness of IIP program}

The effect of the IIP program on occupational safety behaviors among farmers, from general linear model repeated measures ANOVA, adjusted for daily hours working with pesticides (Figure 3), indicated that mean occupational safety behaviors for all four parts in the intervention group (86.04 points) were higher than in the control group (82.50 points) at baseline. Post-intervention, mean occupational safety behavior points had increased to 88.77 points in the intervention group and decreased slightly to 82.06 points in the control group. After focusing on specific occupational safety behaviors (equipment use, pesticide use, ergonomics, and working conditions), results relating to equipment use showed mean safety behavior points in the intervention group (23.04) were higher than in the control group (21.09) at baseline. At follow-up, points had decreased slightly to 22.91 in the intervention group and increased to 22.25 points in the control group. For pesticide use, baseline safety behavior points in the intervention group (29.60) were higher than in the control group (29.14). Post-intervention, points in the intervention group had increased to 30.70 , while they had decreased to 27.12 in the control group. For ergonomics and working conditions, the results were similar: safety behavior points at baseline in the intervention group were higher than in the control group. At follow-up, points were increased slightly in the control group. Unadjusted and adjusted intervention effects on occupational safety behavior scores were similar (Table 2).

We tested the effects of the IIP program on occupational safety behavior points, expressed as absolute magnitudes and proportions of baseline mean points. ${ }^{30,31}$ The IIP program had effectively improved some occupational safety behaviors in the intervention group at follow-up compared with the mean score at baseline: for overall occupational safety behavior,

Table 2 Intervention effects on occupational safety behavior points, expressed as magnitudes and proportions of baseline mean points

\begin{tabular}{|c|c|c|c|c|c|}
\hline \multirow{2}{*}{$\begin{array}{l}\text { Occupational safety } \\
\text { behavior score }\end{array}$} & \multirow{2}{*}{$\begin{array}{l}\text { Overall mean } \\
\text { at baseline }\end{array}$} & \multicolumn{2}{|l|}{ Unadjusted } & \multicolumn{2}{|l|}{ Adjusted } \\
\hline & & Magnitude & $\begin{array}{l}\text { Proportion of } \\
\text { baseline mean }^{\mathrm{a}}\end{array}$ & Magnitude & $\begin{array}{l}\text { Proportion of } \\
\text { baseline mean }\end{array}$ \\
\hline Overall safety behavior & 84.4 & 3.8 & 4.5 & 3.2 & 3.8 \\
\hline Equipment use & 22.1 & -0.9 & -4.1 & -1.3 & -5.9 \\
\hline Pesticide use & 29.4 & 3.2 & 10.9 & 3.1 & 10.5 \\
\hline Ergonomics & 16.3 & 0.4 & 2.4 & 0.3 & 1.8 \\
\hline Working conditions & 16.6 & 1.1 & 6.6 & 1.1 & 6.6 \\
\hline
\end{tabular}

Note: aProportion of baseline mean as percent of baseline mean points. 


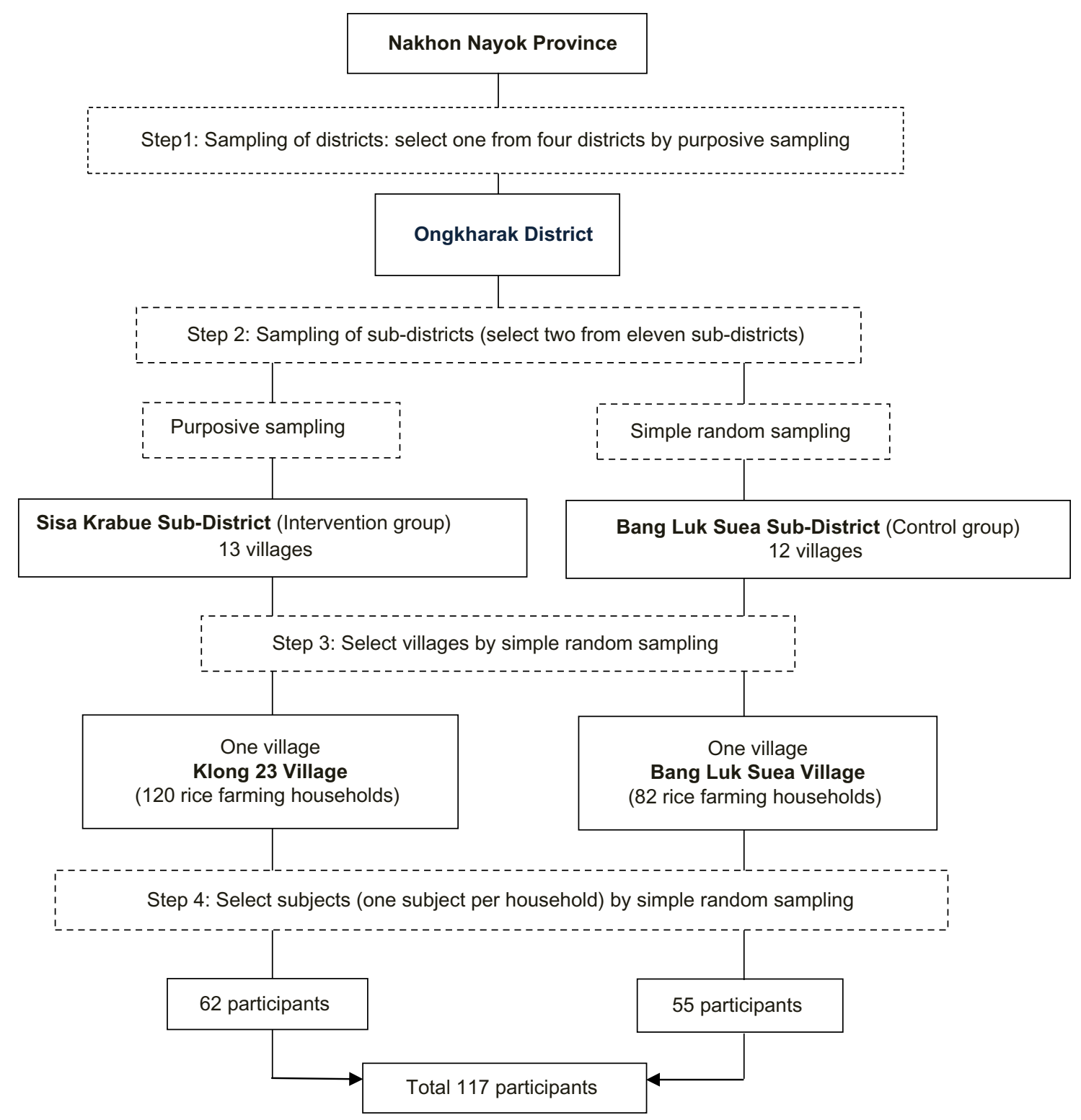

Figure I Sampling technique.

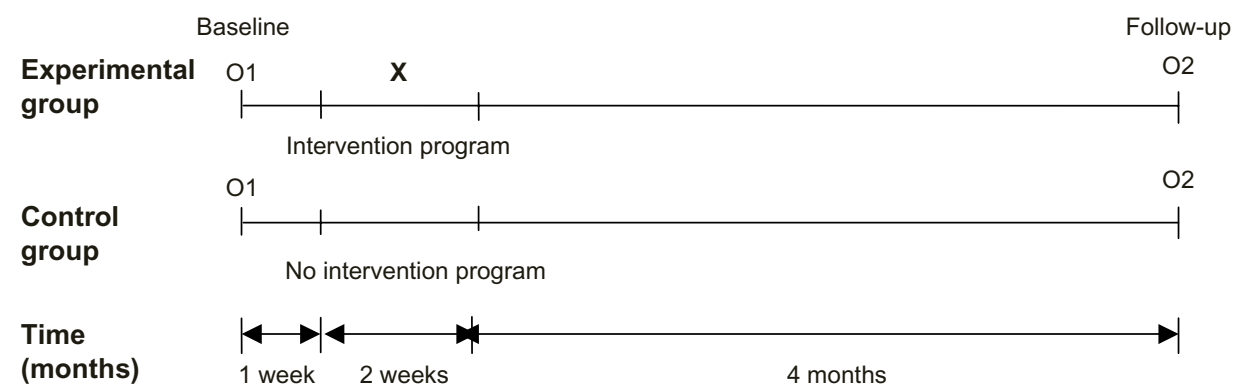

Figure 2 Research design.

Notes: O I, assessment of occupational safety behavior of participants in experimental group and control group before the intervention implementation; O2, assessment of occupational safety behavior of participants in experimental group and control group 4 months after the intervention; X, injury and illness prevention intervention program. 


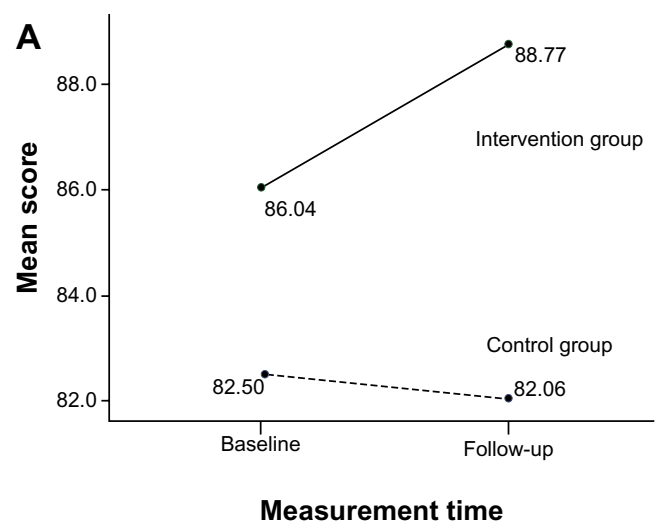

C

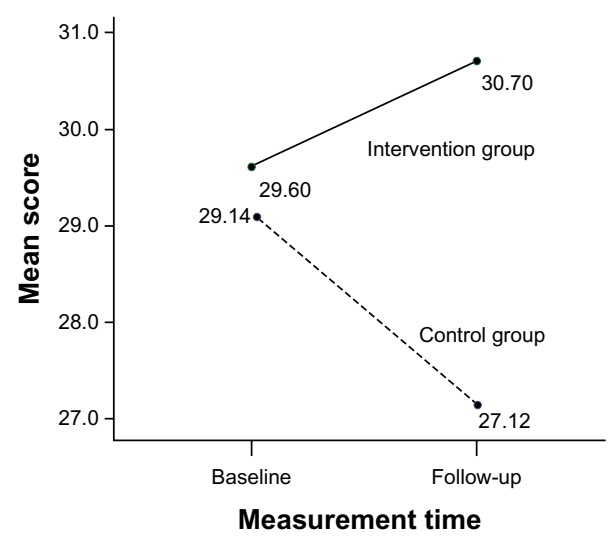

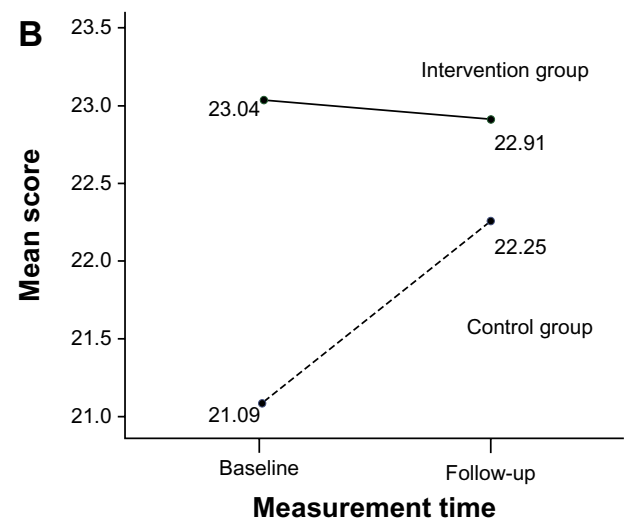

D

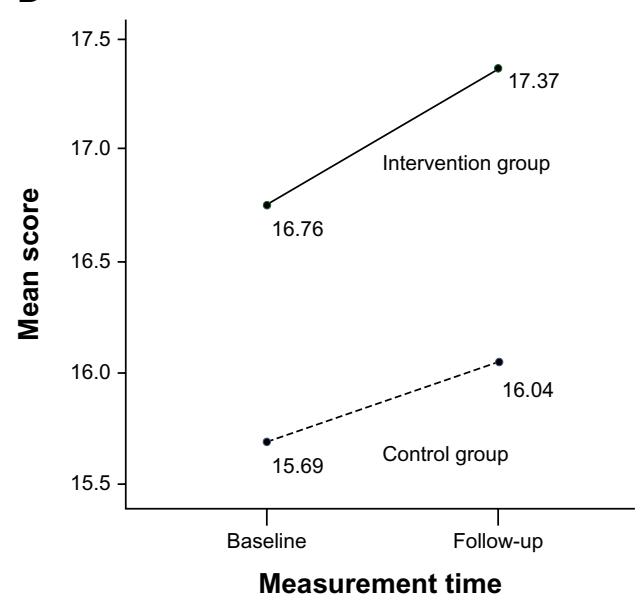

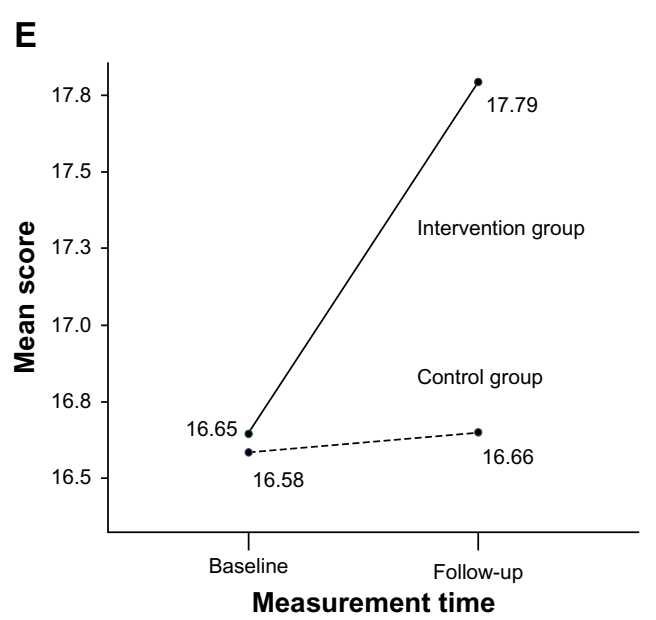

Figure 3 Mean adjusted occupational safety behavior scores by intervention status and measurement time, before and after intervention. (A) Mean overall occupational safety behavior scores. (B) Mean equipment use safety behavior scores. (C) Mean pesticide use safety behavior scores. (D) Ergonomics safety behavior scores. (E) Working conditions safety behavior scores.

the intervention program had effected an increase from baseline score of $3.8 \%$ in the adjusted model and of $4.5 \%$ in the unadjusted model at follow-up. The largest proportional benefit of the intervention, expressed as percentage of baseline score, was observed for pesticide use $(10.5 \%$ in the adjusted model, $10.9 \%$ in the unadjusted model). Working conditions and ergonomics were also increased from the baseline score (6.6\% and $1.8 \%$ in the adjusted model, respectively). Equipment use had an opposite effect $(-5.9 \%$ and $-4.1 \%$ in the adjusted and unadjusted models, respectively). 
Post-intervention, results from the general linear model repeated measures ANOVA (Wilks' lambda from multivariate test) showed that the intervention group had statistically different occupational safety behavior points compared with the control group in pesticide use, as shown in Table 3.

\section{Discussion}

Our program consisted of education methods including group health education and individual health education during home visits. In addition, safety communication, safety inspection, and health surveillance concepts were applied in this program. We combined these concepts to encourage discussion among rice farmers in their groups, letting them know their missing points, such as, that they were less concerned about their health than they were about economics, and were not aware of safety at work. In these cases, we emphasized the importance of safety awareness to good health. The program was developed with the aim of changing behavior and empowering the rice farmers to plan for health and safety at work. Differences in behavior were found between rice farmers who had and who had not participated in the program. The improvement in pesticide safety behavior points among rice farmers suggests that rice farmers who received the IIP program changed some safety behaviors (eg, do not spray pesticides under windy conditions, wear gloves while mixing or touching pesticides, clean all tools thoroughly after using pesticides, and store residual pesticides separately from other implements). Our findings were consistent with those of Raksanam et al, ${ }^{11}$ who found that, post-intervention, the rice farmers in the study group had significantly higher points in behaviors regarding agrochemical exposure, and an in-home pesticide safety assessment. This is also consistent with the findings of a health promotion program in Thai farmers for the safe use of pesticides. ${ }^{32}$ The results showed that this program changed the behavior of farmers to more appropriate use

Table 3 Overall effectiveness of the program on occupational safety behavior score at baseline and at follow-up

\begin{tabular}{llllll}
\hline \multirow{2}{*}{$\begin{array}{l}\text { Occupational safety } \\
\text { behavior score }\end{array}$} & \multicolumn{2}{l}{ Unadjusted $^{\mathrm{a}}$} & & \multicolumn{2}{c}{ Adjusted $^{\mathrm{a}}$} \\
\cline { 2 - 3 } \cline { 6 - 7 } & $\boldsymbol{F}$ & $\boldsymbol{P}$-value & & $\boldsymbol{F}$ & P-value \\
\hline Overall safety behavior & 2.452 & 0.120 & & 1.628 & 0.205 \\
Equipment use & 0.708 & 0.402 & & 1.333 & 0.251 \\
Pesticide use & 10.456 & 0.002 & & 9.185 & 0.003 \\
Ergonomics & 0.243 & 0.623 & & 0.120 & 0.729 \\
Working conditions & 2.206 & 0.140 & & 1.932 & 0.167 \\
\hline
\end{tabular}

Notes: 'General linear model repeated measures ANOVA, Wilks' lambda from multivariate test ( $P$-values were identical to those in the ANOVA test of withinsubject effects).

Abbreviation: ANOVA, analysis of variance. of pesticides (eg, wear long-sleeved shirt, long pants, and always take a bath, and wash their hair with soap and shampoo after spraying). Similarly, a previous study by Sam et al, ${ }^{33}$ who conducted an educational program to promote pesticide safety among pesticide handlers via individual home visits, safety material, and training, showed that their program could improve practice scores for safe pesticide handlers. Stave et $\mathrm{al}^{5}$ conducted an intervention for occupational safety in farming. The intervention approaches were to encourage leaders to help participants analyze the risky incident, and to stimulate the participants to reflect on their own and possible preventive measures in connection to concrete events. The results revealed a significant increase in the safety activity of participants.

One relevant study by Aksorn and Bonaventura ${ }^{34}$ was not performed in the agricultural sector. The concept of safety inspection and accident investigation were similar to this study, which was to find out what was causing the problem and try to solve the cause of work-related injury. The study by Aksorn and Bonaventura indicated that unsafe acts (careless throwing or dropping of objects from a height, not wearing PPE) and unsafe conditions (working surface is not clean and tidy, insufficient level of light) were improved by the implemented safety program, which entailed accident investigation, jobsite inspections, control of subcontractors, and safety incentives.

Rice farmers use large amounts of pesticides, and rice farmers may be especially concerned with health-related pesticide issues. That is, in the intervention program, they paid more attention to pesticide-related contents than to the other parts. In addition, the increase in pesticide safety behavior points might be affected by increasing risk perception, due to risk perception playing an important role in encouraging rice farmers to be aware of their occupational hazards. The change in risk perception among rice farmers might influence their safety behaviors. This is similar to a previous study in Nakhon Nayok Province, Thailand, which found that occupational risk perception positively influenced occupational safety behavior. ${ }^{35}$ For other occupational safety behaviors, working conditions and ergonomics increased from baseline score but did not significantly improve safety behaviors. At the beginning of study, very few participants understood the important concept of ergonomics. Their understanding increased as a result of our group education sessions. Even so, the awareness of ergonomics probably remains limited. Similarly, they might also think that working conditionsrelated injury and illness were not as serious as those related to pesticide use. They may be less concerned with hazards 
from unsafe working conditions. This might be why they did not change some safety behaviors.

In this study, rice farmers were exposed to unsafe working conditions, such as work areas not maintained safely (ie, walkways clear, materials and tools organized), and there were farmers who did not display appropriate safety behavior (keeping sharp equipment in the same place as other equipment, not wearing PPE while working with pesticides, carrying heavy weights a long distance without support equipment). It is necessary to identify and develop further measures to protect and reduce risk-related behavior. Regarding equipment use, working conditions, and ergonomics, some methods such as effective risk communication should be added to increase risk perception. In addition, future studies should maximize connections with local health services to employ complete and accurate records of work-related accidents, injuries, and illnesses. Findings from such studies can be used to develop improved intervention programs to promote occupational health and safety.

The following study limitations should be noted. We did not directly observe the safety behavior of rice farmers. The information was collected via a questionnaire administered in a face-to-face interview. We did not directly observe the safety behavior during farming. Moreover, we evaluated the effects of the intervention program by measuring and comparing changes in mean behavior points 4 months after the intervention. The results might differ with a longer follow-up time.

\section{Conclusion}

The improvement in occupational safety behavior points among rice farmers suggests that the pesticide safety behaviors of rice farmers who received the IIP program positively changed. A combined approach, comprising health education, safety inspections, safety communication, and health surveillance, in which rice farmers receive interventions, may be the effective way to improve some safety behaviors among rice farmers. This study was carried out among rice farmers in the agricultural sector. In our opinion, the findings can reasonably be generalized to rice farmers with similar characteristics, especially in the central region of Thailand.

\section{Acknowledgments}

The authors would like to thank the $90^{\text {th }}$ Year Chulalongkorn Scholarship (Ratchadaphiseksomphot Endowment Fund), Graduate School, Chulalongkorn University, Thailand and the Higher Education Research Promotion and National
Research University Project of Thailand, Office of the Higher Education Commission (AS581A-56 and AS1148A) for partial research grant support.

\section{Disclosure}

The authors report no conflicts of interest in this work.

\section{References}

1. Siriruttanapruk S, Anantagulnathi P. Occupational health and safety situation and research priority in Thailand. Industrial Health. 2004;42(2):135-140.

2. Kumphon P. Pesticide poisoning 2009. Bureau of Epidemiology, Department of Disease Control, Ministry of Public Health. Weekly Epidemiological Surveillance Report, Thailand. 2011;42(17): 257-259.

3. Jones CB, Day L, Staines C. Trends in tractor related fatalities among adults working on farms in Victoria, Australia, 1985-2010. Accid Anal Prev. 2013;50:110-114.

4. Niu S. Ergonomics and occupational safety and health: an ILO perspective. Appl Ergon. 2010;41:744-753.

5. Stave C, Törner M, Eklöf M. An intervention method for occupational safety in farming - evaluation of the effect and process. Appl Ergon. 2007;38(3):357-368.

6. Buranatrevedh S, Sweatsriskul P. Model development for health promotion and control of agricultural occupational health hazards and accidents in Pathumthani, Thailand. Ind Health. 2005;43(4):669-676.

7. Baron S, Estill CF, Steege A, Lalich N, editors. Simple Solutions: Ergonomics for Farm Workers. Cincinnati (OH): US Department of Health and Human Services, Centers for Disease Control and Prevention, National Institute for Occupational Safety and Health; 2001. Available from: http://www.cdc.gov/niosh/docs/2001-111/pdfs/2001111.pdf. Accessed December 7, 2012.

8. Hofmann JN, Crowe J, Postma J, Ybarra V, Keifer MC. Perceptions of environmental and occupational health hazards among agricultural workers in Washington State. AAOHN J. 2009;57(9):359-371.

9. Reese CD. Occupational Health and Safety Management: A Practical Approach. 2nd ed. Boca Raton (FL): CRC Press; 2009:65-71.

10. Monarca D, Cecchini M, Guerrieri M, Santi M, Bedini R, Colantoni A. Safety and health of workers: exposure to dust, noise and vibrations. ACTA Hortic. 2009;845(1):437-442.

11. Raksanam B, Taneepanichskul S, Siriwong W, Robson M. Multi-approach model for improving agrochemical safety among rice farmers in Pathumthani, Thailand. Risk Manag Healthc Policy. 2012;5:75-82.

12. Saari J. Accident epidemiology. In: Karvonen M, Mikheev MI, editors. Epidemiology of Occupational Health. Copenhagen: World Health Organization, Regional Office for Europe;1986:299-316.

13. Dunne E. The Psychology of Working Safely. Dublin: Blackhall; 2000:9.

14. Kawakami T, Khai T, Kogi K. Developing the WIND Training Programme in Asia: Participatory Approaches to Improving Safety, Health and Working Conditions of Farmers. Bangkok: International Labour Organization Subregional Office for East Asia; 2009 : $10-57$.

15. Goetsch DL. Basics of Occupational Safety. Upper Saddle River (NJ): Prentice Hall; 2010:30-43.

16. Studenski R, Dudka G, Bojanowski R. Accidents at work. In: Koradecka D, editor. Handbook of Occupational Safety and Health. Boca Raton (FL): CRC Press; 2010:418-443.

17. Siripanich S, Meaunphueng P. Annual Epidemiological Surveillance Report 2010. Nonthaburi: Bureau of Epidemiology, Ministry of Public Health; 2010. Available from: http://www.boe.moph.go.th/Annual/ aesr2553/AESR53_Part1/B_Part1_53/4853_Pesticide.pdf. Accessed November 20, 2011. Thai. 
18. Panuwet P, Siriwong W, Prapamontol T, et al. Agricultural pesticide management in Thailand: situation and population health risk. Environ Sci Policy. 2012;17:72-81.

19. North-Klong 23 sub-district Health Promoting Hospital. Data records of injury and illness at work showed that 201 case reports among agriculturists during five years (2007-2011). North-Klong 23 sub-district Health Promoting Hospital, Ongkharak district, Nakhon Nayok province, Thailand. 2012.

20. Pathumthani Rice Research Center. Knowledge Management Corner [database on the internet]. Available from: http://ptt.brrd.in.th/web/. Accessed November 6, 2011. Taiwanese.

21. Nakhon Nayok Agricultural Extension Office. Agricultural Information in Ongkharak district. [database on the internet]. 2011. [cited on January 5, 2011]. Available from: http://www.nakhonnayok.doae.go.th/index01. html. Accessed April 10, 2012.

22. Dupont WD, Plummer WD Jr. Power and sample size calculations: a review and computer program. Control Clin Trials. 1990;11(2): 116-128.

23. Jariya W. Effectiveness of Participatory Learning Program on Pesticide Utilization among Agriculturists in Srinakorn District, Sukhothai Province [Masters dissertation]. Bangkok: College of Public Health, Chulalongkorn University; 2006.

24. Murphy DJ. Safety and Health for Production Agriculture. St Joseph (MI): American Society of Agricultural Engineers; 1992:15.

25. Joshi SK. Rice field work and the occupational hazards. JKMC. 2002;4:111-114.

26. Prince $\mathrm{S}$. Overview of hazards for those working in agriculture. In: James E. Lessenger, editor. Agricultural Medicine: A Practical Guide. Porterville (CA): Springer; 2006:29-34.

27. Certification Services, Worker and Employer Services Division. Safety Inspections. Vancouver: WorkSafe BC; 2009:1-30. [database on the internet]. 2009. [cited on 2009 February 20]. Available from:http:// www.worksafebc.com/publications/health_and_safety/by_topic/assets/ pdf/safety_inspections.pdf. Accessed July 8, 2011.
28. US Environmental Protection Agency (EPA). Considerations in Risk Communication: A Digest of Risk Communication as a Risk Management Tool. Washington, DC; USGPO:2002.

29. Covello VT. Risk communication. In: Frumkin H, editor. Environmental Health: From Global to Local. 2nd edition. San Francisco (CA): John Wiley \& Sons, Inc; 2010:1100-1139.

30. Lee JK, Grace KA, Taylor AJ. Effect of a pharmacy care program on medication adherence and persistence, blood pressure, and low-density lipoprotein cholesterol: a randomized controlled trial. JAMA. 2006;296(21):2563-2571.

31. Walker M, Hall A, Basáñez MG. Individual predisposition, household clustering and risk factors for human infection with Ascaris lumbricoides: new epidemiological insights. PLoS Negl Trop Dis. 2011; 5(4):e1047.

32. Janhong K, Lohachit C, Butraporn P, Pansuwan P. Health promotion program for the safe use of pesticides in Thai farmers. Southeast Asian J Trop Med Public Health. 2005;36 Suppl 4:258-261.

33. Sam KG, Andrade HH, Pradhan L, et al. Effectiveness of an educational program to promote pesticide safety among pesticide handlers of South India. Int Arch Occup Environ Health. 2008;81(6):787-795.

34. Aksorn T, Bonaventura HW. Measuring effectiveness of safety programmes in the Thai construction industry. Constr Manage Econ. 2008;26(4):409-421.

35. Santaweesuk S, Chapman RS, Siriwong W. Health risk perception of occupational hazards among rice farmers in Nakhon Nayok province, Thailand. J Health Res. 2013;27(3):197-200.
Risk Management and Healthcare Policy

\section{Publish your work in this journal}

Risk Management and Healthcare Policy is an international, peerreviewed, open access journal focusing on all aspects of public health, policy, and preventative measures to promote good health and improve morbidity and mortality in the population. The journal welcomes submitted papers covering original research, basic science, clinical \& epidemio-

\section{Dovepress}

logical studies, reviews and evaluations, guidelines, expert opinion and commentary, case reports and extended reports. The manuscript management system is completely online and includes a very quick and fair peerreview system, which is all easy to use. Visit http://www.dovepress.com/ testimonials.php to read real quotes from published authors. 